\title{
User views of two psychiatric day hospitals
}

\author{
Guy Holmes, Olivia Dawson, Dominic Waltho, Jenny Beaty and \\ Craig Newnes
}

This report describes one of the largest published surveys of users' views of services, with 287 users returning a 34-liem questionnaire and 80 people interviowed about their views and satisfaction with senvices provided by two psychiatric day hospltals. The combination of questionnaire and interview methodologies provided data such as an overall sattsfaction score (which was relatively high) and satistaction scores with specific aspects of the service, as well as highlighting specific problems and providing recommendations on how to make improvements.

There are many ways of evaluating a service. Sometimes these provide little, if any, data of use or interest to users of services or mental health workers. This study describes how to design and utilise a combination of questionnaire and interview methodologies in order to obtain useful information about a service: how satisfied users are with the service as a whole; what aspects of a service users are dissatisfied with; what users find helpful and unhelpful: what needs to be changed or improved.

The views of patients at two day hospitals were surveyed. The hospitals surveyed provide a range of individual and group interventions for patients with a variety of mental health problems. People are referred by general practitioners (GPs) or workers within the mental health system. The majority of patients have at some time been resident in a psychiatric hospital.

\section{The study}

\section{Questionnaire}

The questionnaire consisted of 17 items from the modified Service Satisfaction Questionnaire (Bond et $a l$, 1992) plus a further 17 items relating to specific issues of relevance and concern to the day hospitals, which had been arrived at through separate meetings with staff from both day hospitals and representatives from a local user group. Patients were asked to indicate their response to each question on a five-point Likert scale (strongly disagree to strongly agree).

The questionnaires were sent out to all current users of the two day hospitals. A covering letter was included that explained the purpose of the study and also asked patients if they wished to meet to discuss any points raised by the questionnaire. Stamped addressed envelopes were included for return of the questionnaire. There was no requirement for patients to identify themselves by name.

\section{Interviews}

The interviews were conducted using the semistructured Survey of Patients' Views (Bond et al. 1992) as a guide. Following discussions with representatives from the user group and with the staff at both units, seven general questions were asked:

(a) What do you think of the day hospital?

(b) What were your first impressions on coming?

(c) What have you found helpful about coming here?

(d) What has not been helpful?

(e) Has there been a situation where you have felt uncomfortable in any way?

(f) How do you think things could be improved?

(g) Is there anything else you would like to say about the day hospital?

\section{Sample}

Six hundred and fifty-seven questionnaires were sent to patients at the two day hospitals of which 287 were returned (a response rate of $44 \%$ ). Ninety-five patients said they were interested in being interviewed of which 80 (40 from each hospital) were randomly selected for interview.

\section{Findings}

\section{Questionnaire}

Responses to the questions were converted from the five-point Likert scale (strongly agree to strongly disagree) into satisfaction scores ranging from 1 (very low satisfaction) to 5 (very high 
satisfaction). Three was the mid-point score, indicating neither satisfied nor unsatisfied.

The overall satisfaction score per question was 3.9 for day hospital one and 4.0 for day hospital two. (The mean scores for each question are available from the authors upon request.)

Highest satisfaction was around ways in which staff treated clients (e.g. with respect, taking their problems seriously and not discussing them in front of others) and with the treatments, especially individual counselling. Lowest satisfaction related to the stigma of attending the day hospitals, fears about breaking rules and aspects of the buildings including poor accessibility for disabled people and the (inhospitable) reception areas.

Some concerns that user groups and staff had held about the day hospitals before the survey was conducted were only confirmed by a small minority of patients. For example, less than $6 \%$ of respondents felt unable to turn down a treatment if they wanted to and more than $50 \%$ found the medication useful. For some questions, although the majority were satisfied, a significant minority were not e.g. $20 \%$ of respondents were concerned about not being offered a choice of gender of therapist and $22 \%$ were concerned about not being told about the wanted and unwanted effects of their treatment.

\section{Interviews}

Analysis of the interview data followed general recommendations for content analysis regarding grouping and subgrouping of text (Moser \& Kalton, 1971; Dey, 1993). Categories (highlighted in italics below) were generated from the raw data, then each statement was rated by two people as to which category it fitted. Interrater reliability was high ( $\kappa$ of 0.85 and 0.77 for each day hospital). As in the questionnaire data, there was considerable overlap in the comments made about each day hospital.

Patients felt that the day hospitals provided them with a place of sanctuary, a refuge and a sense of security. The hospitals were felt to be "a safe place to go' and helped patients have an inner sense of security and consequent wellbeing: 'It's been a retreat, a haven where you can calm down'. The atmosphere of the day hospitals appeared crucial to the likelihood of them being perceived as helpful. The atmosphere of both places was described as friendly, relaxed, peaceful and caring: 'I was expecting a hospital, institutional type of place; instead it feels restful'. In relation to the treatments on offer, talking and counselling were viewed as very helpful: 'One-toone when I first came here really sorted me out. Being able to talk to someone who understands is good'. The keyworker system, when working well, was uniformly praised, although two patients found talking to other patients just as helpful as talking to staff.

Eight people found group work difficult, especially at first, but eventually the majority found it rewarding. Groups singled out for specific praise included assertiveness training, relaxation, art therapy, psychodrama, women's group, pottery. anxiety management and social confidence. The majority of patients expressed satisfaction with the support provided by staff, describing staff attitudes as friendly, caring and understanding. Patients appreciated that they were not patronised, 'dehumanised' or 'treated as just a number': 'I liked being considered, valued as an important person'.

Contact with other patients was also seen as helpful-it provided an opportunity for social contact and gave people the chance to be with other people with similar problems: There are people around that I can talk to who can understand; they make me feel less of a freak. I'm not the only one'; 'I am ill and broke because of unemployment but I can share with others who have the same experiences'.

In addition, being provided with information and having a feeling of some power, a 'say', over what happens to them at the day hospitals, was referred to by many patients and linked to good outcome. Being able to make an informed choice about treatments (counselling groups, medication) was highly valued.

However, the interviews also revealed areas of the service that patients were not happy with. Patients were reasonable and innovative in their suggestions for change, and, these were incorporated into a report to the adult services directorate. Each day hospital was asked to consider the recommendations of the report with a view to implementing them within a six-month period. The problem areas relating to the service included the following.

Staff appeared to be continually engaged in patient-related activities, with a result that no one was available when a patient became distressed. It was recommended that there be sufficient staff for one member to be 'on call' or 'floating'. In addition, many staff did not seem aware of patients' difficulties in asking for help, and patients' fears of 'breaking the rules'. It was recommended that staff explore patients' fears on these issues, and review the rules and actual or perceived sanctions for breaking them.

The waiting areas in both buildings were perceived as inhospitable, lacking in privacy. and anxiety provoking: "Confidentiality is a problem. People can see you waiting, you are on edge all the time waiting for the door to open'. Although space was at a premium at both hospitals, it was clear that for many patients the waiting area was unacceptable - it increased their anxiety. Although staff did not see this as a 
high priority, patients clearly did, and an alternative area was recommended in both hospitals.

Staff felt they gave patients a lot of information, however patients felt that they wanted more. They suggested leaflets or booklets about admission and discharge, the keyworker system and about treatments and their side-effects. Patients offered to assist in the compilation of these.

Patients expressed some dissatisfaction with group work. Groups frequently consisted of too many people, making patients' anxieties about attending and self-disclosure unmanageably high. Rather than have groups of up to 25 people, it was recommended that a maximum of 8-10 people attend therapy groups.

\section{Comment}

This study, a compilation of questionnaire and interview methodologies, produced numerous benefits. It provided each day hospital with an overall measure of satisfaction, a score with which it can evaluate changes in user satisfaction over time. It provided measures of satisfaction relating to various aspects of the service (the staff, building, treatments, atmosphere, stigma, travel, etc.) and tested out (and largely allayed) fears that user groups and staff had about the quality of service provided at the hospitals. The interview data helped the researchers and staff to make sense of the questionnaire data and was invaluable as a source of suggestions from users on how to improve many aspects of the service. It indicated that the most important factors in producing therapeutic benefits are the ways in which patients are treated rather than the treatments prescribed for them.

User groups had an important role in the design of the study. One improvement, however, would have been to have users and ex-users of services conducting the interviews (rather than independent researchers who, although not directly connected with the day hospitals, were trust staff). Another improvement would have been to collect personal and demographic data on the clients (e.g. age, gender, reason for referral, change in symptoms since referral). This could have been included in the data analysis, and could also have been used to compare the sample of respondents with those who did not respond. Although the questionnaire response rate was below $50 \%$, it is typical for postal questionnaire surveys (Moser \& Kalton, 1971). Although we are unable to verify that this is a representative sample, the sample size is large: nearly 300 users have expressed their views on services they receive. The users have had their say. Staff and management now have an opportunity to build upon aspects of the service users are satisfied with and have linked to good outcomes, and to change parts of the service, hopefully with users' help, that are counterproductive and not helpful.

\section{Acknowledgements}

We thank Anne MacLachlan and Sam Solomon for their help with the interviewing and statistical analysis of the results.

\section{References}

BOND, J., NEWNES, C. \& MOONIARUCH. F. (1992) User views of the inpatient psychiatric service at Shelton Hospital. Clinical Psychology Forum, 49, 21-26.

DEY, I. (1993) Qualitative Data Analysis. London: Routledge.

Moser, C. A. \& KALTON, G (1971) Survey Methods in Social Investigation (2nd edn). Aldershot: Dartmouth.

*Guy Holmes, Clinical Psychologist, Olivia Dawson, Assistant Psychologist, Dominic Waltho, Assistant Psychologist, Jenny Beaty. Assistant Psychologist, and Craig Newnes, Consultant Clinical Psychologist, Shropshire's Mental Health NHS Trust, Psychology Consultancy Service, 130 Abbey Foregate, Shrewsbury, Shropshire SY2 6AX

*Correspondence 